\title{
The quality of integrated reproductive health services: perspectives of clients in KwaZulu-Natal, South Africa
}

\author{
P Maharaj, PhD, School of Development Studies, University of KwaZulu-Natal \\ C Munthree, Masters in Population Studies, School of Development Studies, \\ University of KwaZulu-Natal
}

\begin{abstract}
The focus of family planning programmes has shifted away from an emphasis on controlling fertility towards helping individuals achieve their reproductive goals. This article seeks to expand knowledge about the quality of integrated services from the perspective of clients at health facilities in KwaZulu-Natal. The results from 300 structured interviews with clients visiting health facilities found that overall quality of services was relatively high. However, the quality of services varied somewhat between rural and urban areas. Clients visiting urban health facilities reported greater satisfaction with services than clients visiting rural health facilities. The interviews with clients suggests that existing efforts to integrate services has had limited success. Clients were rarely offered an expanded range of services during their visit. In most cases, clients only received services for which they presented at the health facility.
\end{abstract}

\section{Introduction}

At the 1994 International Conference on Population and Development, 180 countries pledged their commitment to meeting the reproductive needs of sexually active men and women. The recommendation was to provide an integrated package of reproductive health services - including the management of sexually transmitted infections (STIs)through existing maternal and child health (MCH) and family planning programs (United Nations 1995). This shift towards integration was based on the belief that integrated services may be the most convenient and effective way of providing cost effective and better quality services to sexually active men and women. However, despite international agreement on the need for integration, little consensus exists about the definition of integration. Integration means different things to different stakeholders (Lush, Cleland, Walt \& Mayhew 1999: 771; Lush 2002:71). Essentially, two sets of STI activities can be integrated into family planning: those relating to STI/HIV prevention and those relating to STI management. In addition, the promotion and distribution of condoms may be introduced into family planning as a new activity (Dehne \& Snow 1998: 19).

In theory, the provision of integrated services is positive and holds great potential for combating the spread of the STIs, particularly in countries such as Africa where access to resources are limited and the prevalence is high (Hardee,
Agarwal, Luke, Wilson, Pendzich, Farrel \& Cross 1999:5). However, Mayhew (2000:115) argues that, under certain circumstances, integrated services may overburden current health facilities and health workers to such an extent that it may lead to a decline in the quality of care. Moreover, it may lead to inefficient treatment and care of STI/HIV patients (Mayhew 2000: 115).

One of the primary objectives of the Department of Health in South Africa is "to reduce disparities and inequities in health service delivery and increase access to improved and integrated services, based on primary health principles" (Department of Health 1997:14). Improving quality of care has emerged as one of the priority objectives of the Department of Health (Ibid). Quality of care is likely to influence sustained use of services (Jain 1989: 13; Bruce 1990: 77-78). The aim of the study was to ascertain and describe the quality of integrated services from the perspective of clients.

\section{Method}

\section{Research Design}

This was a descriptive study to describe client's perception of the quality of integrated reproductive health services. The data for this study was derived from structured interviews conducted with clients leaving the health facili- 
ties. In structured interviews the questions are predetermined, with the general use of more close-ended than openended questions (Judd, Smith \& Kidder 1991:260).

\section{Setting}

This study was conducted in an urban and rural area in KwaZulu-Natal- the province experiencing a severe HIV epidemic among antenatal attendees of $33 \%$ (Department of Health 1999). KwaZulu-Natal is predominantly African, with isiZulu being the main language. The urban and rural areas were selected because of high levels of HIV infection among antenatal clinic attendees. In 1998, the level of HIV infection for the rural area was estimated at between $25 \%$ and $33 \%$ and for the urban area between $33 \%$ and $42 \%$ (Department of Health 1999). In the urban and rural area. four health facilities were selected. The study was limited to government facilities because the vast majority of African men and women rely on the government for meeting their health needs.

\section{Data Collection}

Interviews with providers may sometimes elicit responses that reflect idealised rather actual behaviour (Simmons \& Elias 1994: 3). For this reason it was decided to conduct structured interviews with clients. The aim of the exit interviews was to determine clients' experiences and perception of the quality of services. Questions asked to clients included socio-demographic information, motive for visit, types of questions asked by provider and acceptability of services. The fieldwork for the study took place from February to April 2001. All the interviews were conducted by specially trained field workers of the same sex as the respondent. Each interview lasted approximately 20 minutes.

Structured interviews were held with 300 clients. There were 100 clients of family planning services, 100 clients of $\mathrm{MCH}$ services and 100 clients of STI services. Of the 100 interviews with clients of family planning services, 50 were new clients and 50 were revisit clients. It was decided that the sample size was sufficient to allow for comparison between the different categories of users of services. Almost half of the respondents were living in the urban area and half were living in the rural area. The majority of the 300 clients $(81 \%)$ were women. This aspect of the sample was anticipated, because women were more likely to visit health facilities for family planning and $\mathrm{MCH}$ services. Men were more likely to visit health facilities for STI services. The mean age of clients was 24.7 and the mean number of children was 1.4.

\section{Reliability and validity of the research instrument}

Reliability refers to the consistency of measurements (Burns \& Grove 2001:395). The reliability of the research instrument was enhanced by checking and rechecking all the items in the questionnaire by researchers who were not part of the research team. The researchers also felt that it was important to ensure that the research instrument met the criteria of content validity. Content validity is usually determined by ascertaining whether the measuring instrument includes all the essential elements relevant to the item being measured (Burns \& Grove 2001: 330). An in-depth literature search was conducted and important aspects were included in the research instrument. Also, other researchers were used to judge the relevance of items in the research instrument.

\section{Ethical considerations and permission}

In order to gain access to health facilities, permission was first obtained from the provincial department of health in KwaZulu-Natal to conduct the research. Ethical approval to conduct the study was obtained from the University of Natal before the department of health consented to the research. Once permission was obtained, telephonic appointments were arranged to visit the health facilities. All clients were randomly approached after they had completed their consultation with the provider and asked if they would

\section{Table 1: Percentage of clients agreeing with specific statements about the services that they received from providers}

\begin{tabular}{|l|l|l|}
\hline Statement & Urban \% & Rural \% \\
\hline Staff were friendly and helpful & 80 & 65 \\
\hline Staff treat me with respect & 84 & 63 \\
\hline Staff were difficult to understand & 7 & 31 \\
\hline Staff were helpful in providing information & 77 & 65 \\
\hline I felt that there was insufficient time to ask questions & 37 & 53 \\
\hline Staff are usually too busy to answer my questions & 29 & 56 \\
\hline Staff answered all my questions to my satisfaction & 60 & 32 \\
\hline Staff gave me the opportunity to ask questions & 59 & 13 \\
\hline N & 150 & 150 \\
\hline
\end{tabular}


Table 2: Percentage of clients agreeing with specific statements about the services that they received from providers

\begin{tabular}{|l|l|l|}
\hline Statement & Urban \% & Rural \% \\
\hline There was insufficient privacy during the consultation & 10.7 & 34.0 \\
\hline The waiting time for the consultation was reasonable & 54.0 & 32.7 \\
\hline I came away from the clinic feeling that I had received good quality of care & 63.3 & 58.0 \\
\hline $\mathrm{N}$ & 150 & 150 \\
\hline
\end{tabular}

be willing to participate in their study. The interviewer explained the purpose of the study and assured clients that they were not employed by the health facility. Clients were also given the assurance that their responses would be kept strictly confidential. All the interviews took place in a private place, away from providers and other clients.

\section{Data Analysis}

Initially, the field workers checked all questionnaires for completeness and inconsistencies. The data was coded and entered into Epi Info using the standard data entry package. For verification purposes, the data was double entered. The SPSS software was used to analyse the data obtained from the questionnaires used during the structured interviews with the 300 clients. Descriptive statistics were utilised using frequencies, percentages and tables.

\section{Results}

\section{Interpersonal Relations}

Interpersonal relations between providers and clients are seen as the cornerstone of good quality services (Bruce 1990). Clients were asked to reveal their perception of providers by expressing their agreement or disagreement with specific statements (see Table 1). In general, clients expressed positive feelings towards providers. Seventy three percent of clients perceived providers as friendly and helpful, while $74 \%$ of clients felt that the providers treated them with respect. The majority of clients $(81 \%)$ felt that the providers were easy to understand. However, perceptions of interpersonal relations varied somewhat between rural and urban areas.

An important component of interpersonal relationship is making clients feel comfortable enough to be able to ask questions (Miller, Jone \& Horn 1998: 50). A sizeable minority $(23 \%)$ of clients reported that they were not provided with all the information they wanted during the consultation. Interestingly, $45 \%$ of clients felt that there was not sufficient time to ask questions. In addition, $54 \%$ of clients felt that providers did not answer all their questions to their satisfaction. More than two-fifths of all clients (42\%) felt that the providers were too busy to answer their questions. It is worth noting that $31 \%$ of rural clients, compared with $7 \%$ of urban clients, felt that staff were difficult to understand. Overall, clients presenting at rural facilities were more likely than clients presenting at urban facilities to express dissatisfaction with their interaction with providers.

\section{Appropriateness and acceptability of services}

Services should be designed with the needs of clients, rather than the convenience of providers (FHI 1994). A common complaint is the lack of privacy during consultations. Nearly $23 \%$ of clients felt that there was not sufficient privacy during their consultation, while nearly $56 \%$ of clients felt that the waiting time for the consultation was unreasonably long. Clients were asked to judge the overall quality of care that they received on their visit to the health facility, as shown in Table 2. More than half of clients felt that they had come away from the health facility feeling that they had received good quality care, but again there were differences between the urban and rural area.

\section{Choice of Methods}

The availability of a range of methods of contraception has been considered a central element of quality of care because it is likely to influence client satisfaction, contraceptive acceptance and continuation (Koenig, Hossain \& Whittaker. 1997: 8). Knowledge of at least one method is an important condition for use of contraception, but knowledge of more than one method is required to make an informed choice and is associated with a greater probability of adopting and continuing use of a method of contraception (Rutenberg, Ayad, Ochoa \& Wilkinson 1991:5). The choice of methods of contraception offered to clients was fairly limited, as shown in Table 3 . Almost $35 \%$ of clients were not given any information about any method of contraception. $\mathrm{MCH}$ clients were least likely to receive any information about any method of contraception. Only 15\% of $\mathrm{MCH}$ clients received any information about any method of contraception. Not surprising, $98 \%$ of family planning clients were told of at least one method. Only two family planning clients said that they did not receive information on any method during their visit to the health facility.

Obviously, an important prevention approach in a setting with a severe HIV epidemic is the promotion of condoms as a method of dual protection. Clients were asked whether the provider had discussed condoms. Providers were much more likely to mention condoms to STI clients rather than family planning clients. Family planning clients were more likely to receive information about other more highly effec- 
Table 3: Percentage of clients given information about a number of methods

\begin{tabular}{|l|l|l|l|}
\hline \multirow{2}{*}{ Number of Methods } & \multicolumn{3}{|c|}{ Type of Client } \\
\cline { 2 - 4 } & Family Planning & MCH & STI \\
\hline 0 & 2 & 85 & 19 \\
\hline 1 & 48 & 4 & 80 \\
\hline 2 & 26 & 10 & 1 \\
\hline $3+$ & 24 & 1 & 0 \\
\hline$N$ & 100 & 100 & 100 \\
\hline
\end{tabular}

tive methods of preventing pregnancy. The most commonly mentioned methods among family planning clients were the injection, followed by the pill and the condom. New clients were more likely than re-visit family planning clients to receive information about more than one method. Of the new family planning clients, $24 \%$ received information about one method, $34 \%$ about two methods and $42 \%$ three methods or more. Of the re-visit clients, $72 \%$ received information about one method, $18 \%$ on two methods and $6 \%$ of three or more methods and $4 \%$ did not receive any information.

\section{Technical Competence}

Technical competence involves factors such as adherence to protocols and performance of clinical techniques (Bruce 1990). Providers have an important role to play in informing clients about family planning. According to Westoff and Bankole (1995:18), women who have knowledge of contraceptive methods and are aware of sources of supplies are less likely to have an unmet need. During their consultation with clients, providers were expected to identify fertility intentions and needs and encourage those with an unmet need to seek services (Ndhlovu 1999:120). This usually involved asking clients about their sexual relations, fertility intentions and past contraceptive use. Only $26 \%$ of $\mathrm{MCH}$ clients were provided with individual information about family planning during their consultation and even fewer STI clients $(11 \%)$. Only $13 \%$ of $\mathrm{MCH}$ and $3 \%$ of STI clients were asked if they had ever used a method of contraception and $16 \%$ of $\mathrm{MCH}$ and $9 \%$ of STI clients were asked if they were interested in using a method of contraception. Moreover, only $7 \%$ of $\mathrm{MCH}$ and $4 \%$ of STI clients were asked if they have any concerns about using any method and only $3 \%$ of $\mathrm{MCH}$ and $2 \%$ of STl clients were asked if they had discussed family planning with their partner.

Clients of family planning and $\mathrm{MCH}$ are usually sexually active and at risk at of STIs and should ideally be screened (Miller, Jone \& Horn 1998:52-53). As many women in developing countries routinely attend family planning and $\mathrm{MCH}$ clinics, these are potentially important opportunities to detect and manage STIs more effectively (Dehne, Snow \& O'Reilly 2000: 628). An essential aspect requires the provider to ask clients about their sexual relations. In general, the screening of family planning and $\mathrm{MCH}$ clients for STIs does not routinely occur, as shown in Table 5 . Only $15 \%$ of family planning and $\mathrm{MCH}$ clients were asked any behavioral questions to identify high-risk behavior. An inexpensive method of assessing risk is interviewing clients about the presence of symptoms (Keller 1995: 20). Few clients (9\%) reported that the provider asked them about the presence of symptoms of STIs, though more $\mathrm{MCH}(12 \%)$ than family planning $(6 \%)$ clients responded positively. In addition, less than $5 \%$ of family planning and $\mathrm{MCH}$ clients were asked if they have any concerns about getting STIs or whether they had discussed STIs with their partner.

\section{Mechanisms to ensure continuity of care}

Mechanisms to ensure continuity reflect the procedures that facilities may have established to encourage acceptors to continue using services (Brown, Tyane, Betrand, Lauro, Abou-Ouakil \& Demaria 1995:161). The purpose of improving quality of care is to encourage an ongoing relationship between client and service provider and continued use of services among clients (Kim, Rimon, Winnard, Corso, Mako, Lawal, Babalola \& Huntington 1995: 119). Providing clients with follow up appointments at the end of their consultation session is one way to encourage continuity. Clients were asked if they were told when to return for a follow up visit. The analysis showed that $69 \%$ of clients were told whether they needed to return for a follow up visit. Clients visiting urban health facilities (74\%) were more likely than clients visiting rural health facilities $(63 \%)$ to be provided with this information. However, it is important to realise that this is no guarantee that cli- 
Table 5: Percentage of family planning and MCH clients that were screened in specified ways for STIs

\begin{tabular}{|l|l|l|}
\hline & Family & MCH \% \\
\hline & Planning \% & \\
\hline Number of sexual partners & 1 & 4 \\
\hline Partner's other sexual partners & 1 & 1 \\
\hline Presence of STI symptoms & 6 & 12 \\
\hline Client's concern about STIs & 5 & 5 \\
\hline Discussed STIs with partner & 5 & 2 \\
\hline $\begin{array}{l}\text { Performed a pelvic examination } \\
\text { N }\end{array}$ & 0 & 5 \\
\hline
\end{tabular}

ents will comply.

\section{Conclusion}

It is important to begin this discussion with a cautionary note with regard to the limitations of exit interviews. A major drawback of exit interview is that it excludes individuals who do not visit health facilities or who are turned away (Simmons \& Elias 1994: 9). Simmons and Elias (1994: 9) argue that interviewing clients in close proximity to health posts may lead to courtesy bias, whereby clients do not want to be perceived as rude and ungrateful. Sometimes there is a tendency among clients to report high levels of satisfaction with services, even when service quality may be poor or marginal (Simmons \& Elias 1994: 9). In general, clients described providers as friendly and helpful. However, a sizeable fraction of clients complained that they did not get an opportunity to raise concerns with providers. This finding is consistent with other research conducted in South Africa's public health services, which found that client-provider interaction was limited to terse instructions and cursory explanations by providers (Mathews, Van Rensburg, Schierhout, Coetzee, Lombard, Fehler \& Ballard 1998:692). It is possible that quantity of services is being traded for quality of services. Thus, integration of services in an already burdened facility may lead to the overall quality of care being less than satisfactory (Dehne, Snow \& O'Reilly 2000: 628). In the interviews clients also complained that there was a general lack of privacy. The lack of privacy may affect client's willingness to provide sensitive information.

Clients did not receive information about a range of contraceptive methods that would have allowed them to make an informed decision. Often providers recommend highly effective methods of preventing pregnancy to family planning clients that offer little or no protection against STIs/ HIV. Condoms are more likely to be associated with disease- rather than pregnancy-prevention. This is consistent with another study in South Africa that found that condoms are not seen as an effective method of family plan- ning (Abdool-Karim, Abdool Karim, Preston-Whyte 1992: $360-362)$

Clients often receive services for which they present at health facilities. Virtually all family planning and $\mathrm{MCH}$ clients reported not undergoing any of the STI detection procedures, which usually includes taking a medical history, performing a general physical examination. asking the client risk assessment questions, and also, performing a pelvic examination. In addition, clients often leave health facilities without receiving all the information they require on family planning. Providers are therefore missing opportunities for providing clients with information on preventing pregnancy and STIs (including HIV/AIDS).

\section{Recommendations}

Studies show that clients who feel that they are treated with respect, have had their questions fully answered and have received appropriate guidance are more likely to correctly and consistently use family planning and other reproductive health services (Bruce 1990: 62-64; Outlook 1999: 2-4). Given the widely held belief that quality of services influences reproductive goals, an urgent need exists for improving client-provider interaction at health facilities (Bruce 1990; Jain 1989).

A lack of privacy may prevent some clients and providers from participating in a full exchange of information during the consultation (Askew, Mensch \& Adewuji 1994: 5). Some clients complained that there was a lack of privacy and time. In the short term, the feasibility of services is dependent on the adequacy of the existing infrastructure (Hardee et al. 1998:8).

Health facilities are seen as an appropriate and acceptable setting for communicating messages about the risk of pregnancy and STIs/HIV (Pachauri 1994: 331). The aim of prevention activities is to inform, educate and counsel clients on health seeking behaviour to reduce the risk of unwanted pregnancy and STIs/HIV (Askew \& Maggwa 2002; Dehne et al. 2000). It is important to bear in mind that providers may experience 'role expansion', being asked to undertake tasks for which they are not prepared. This may reduce workers' morale and motivation and can ultimately lead to a decline in the overall quality of the services. Technical competence of providers is likely to be heavily dependent on on-going training and also, the availability of clear guidelines.

\section{Reference}

ABDOOL KARIM,Q., ABDOOL KARIM,SS, PRESTONWHYTE, E.M. 1992: Teenagers seeking condoms at family planning services. Part I. South African Medical Journal. 82(5): $360-362$.

ASKEW, I., MENSCH, B., ADEWUYI, A. 1994: Indicators for measuring the quality of family planning services in Nigeria. Studies in Family Planning. 25(5): 
268-283.

ASKEW, I. \& MAGGWA, N. 2002: Integration of STI Prevention and Management with Family Planning and Antenatal Care in Sub-Saharan Africa: What more do we need to know? International Familv Planning Perspectives, 28(2): $77-86$.

BRUCE, J. 1990: Fundamental elements of the quality of care: a simple framework. Studies in Family Planning. $21(2)$ : $61-91$.

BROWN, L., TYANE, M., BETRAND, J., LAURO, D., ABOU-OUAKIL, M., DEMARIA, L. 1995: Quality of care in family planning services in Morocco. Studies in Family Planning. 26(3): 154- 168.

BURNS, N \& GROVE, SK. 2001: The practice of nursing research: conduct, critique and utilization. Philadelphia: Saunders.

DEHNE, K. \& SNOW, R. 1998: Integrating STD management into family planning services. What are the benefits? Heidelberg: University of Heidelberg, Department of Tropical Hygiene and Public Health. 1-79.

DEHNE, K., SNOW, R. \& O'REILLY, K.R. 2000: Integration of Prevention and care of sexually transmitted infections with family planning services: what is the evidence for public health benefits? Bulletin of the World Health Organisation. 78(5): 628-639.

DEPARTMENT OF HEALTH. 1997: White Paper for the Transformation of the Health System in South Africa. Pretoria: Government Gazette.

DEPARTMENT OF HEALTH 1999: National and Provincial HIV and Syphilis Sero-prevalence Survey of Women Attending Public Antenatal Clinics in South Africa - 1998. Pretoria: Department of Health.

FAMILY HEALTH INTERNATIONAL (FHI) 2003: Maximising Access to Quality Family Planning and Reproductive Health Services. USA: FHI.

HARDEE, K., AGARWAL, K., LUKE, N., WILSON, E., PENDZICH, M., FARRELL, M. \& CROSS, H. 1999: Reproductive Health Policies and Programmes in Eight Countries: Progress since Cairo. International Family Planning Perspectives. 25(supplement): 2-9.

JAIN, A. 1989: Fertility reduction and the quality of family planning services. Studies in Family Planning. 20(1): 1-16.

JUDD, CM., SMITH, ER \& KIDDER, LH. 1991: Research Methods in Social Relations. Philadelphia: Holt, Rinehart and Winston Inc.

KIM, Y., RIMON,J., WINNARD, K., CORSO, C., MAKO, I.V., LAWAL, S., BABALOLA, S. \& HUNTINGTON, D.
1992: Improving the quality of service Delivery in Nigeria. Studies in Family Planning, 23(2): 118-127.

KELLER, S. 1995: Good reproductive health involves many services. Network. 16(1).

KOENIG, M. HOSSAIN, M. \& WHITTAKER, M. 1997: The Influence of Quality of Care upon Contraceptive Use in Rural Bangladesh. Studies in Family Planning. 28(4): 278289.

LUSH, L. 2002: Service Integration: An Overview of Policy Developments. International Family Planning Perspectives. 28(2): 71-76.

LUSH, L., CLELAND, J., WALT, G., \& MAYHEW,S. 1999: Integrating Reproductive Health: Myth and Ideology. Bulletin of the World Health Organisation. 77(9): 771-777.

MATHEWS, C., VAN RENSBURG, A., SCHIERHOUT,G., COETZEE, N., LOMBARD, CJ., FEHLER, HG \& BALLARD, RC. 1998: An assessment of care provided by a public sector STD clinic in Cape Town. International Journal of STD and AIDS. 9: 689-694.

MAYHEW, S. 2000: Integration of STI services into FP/ $\mathrm{MCH}$ services: health services and social contexts in rural Ghana. Reproductive Health Matters. 8(16): 112124.

MILLER, K., JONE, H. \& HORN, M.C. 1998: Indicators of Readiness and Quality: Basic Findings. Clinic-Based Family Planning and Reproductive Health Services: Findings from Situation Analysis Studies. Edited by K. Miller, I. Askew, M. Horn and L. Ndhlovu. New York: Population Council.

NDHLOVU, L. 1999: Quality in the Context of Kenya's Integrated Reproductive Health Services. London: University of London.

OUTLOOK. 1999: Improving interactions with clients: a key to high quality services. Outlook. 17(2): 1-8.

PACHAURI, S. 1994: Relationship between AIDS and Family Planning Programmes: a rationale for developing integrated reproductive health services. Health Transition Review 4. (Supplement): 321-347.

RUTENBERG, N., AYAD, M., OCHOA, LN AND WILKINSON, M. 1991: Knowledge and use of contraception. Calverton, Maryland, USA, DHS Comparative Studies, Macro International.

SIMMONS, R. \& ELIAS, C. 1994: The Study of ClientProvider Interactions: A Review of Methodological Issues. Studies in Familv Planning. 25(1): 1-16.

UNITED NATIONS 1995: Population and Development, Programme of Action Adopted at the International Conference on Population and Development, Cairo, Sept 5-13, 1994. Vol 1. New York: Department for Economic and Social Infor- 
mation and Policy Analysis, UN.

WESTOFF, C. \& BANKOLE, A. 1995: Unmet need: 19901994. Calverton, Maryland, USA, DHS Comparative Studies, Macro International. 